\begin{tabular}{|c|c|c|}
\hline $\begin{array}{l}\text { PKS } \\
\text { PUBLIC } \\
\text { KNDOLEDGE } \\
\text { PROJECT }\end{array}$ & $\begin{array}{c}\text { REVISTA DE GEOGRAFIA } \\
\text { (RECIFE) } \\
\text { http://www.revista.ufpe.br/revistageografia }\end{array}$ & $\begin{array}{l}\text { OJS } \\
\text { OPEN } \\
\text { JOUNAL } \\
\text { SYSTEMS }\end{array}$ \\
\hline
\end{tabular}

\title{
CIRCUITOS ALIMENTARES DE PROXIMIDADE: CONCEITOS, DEFINIÇÃO E PRÁTICAS
}

\author{
Marcones Ivo Braz ${ }^{1}$; Mônica Cox de Britto Pereira ${ }^{2}$ \\ ${ }^{1}$ Mestre pelo Programa de Pós-Graduação em Geografia da UFPE (PPGEO). E-mail: \\ marconesbraz@gmail.com \\ ${ }^{2}$ Professora Associada do Departamento de Ciências Geográficas e do Programa de Pós-Graduação em Geografia da UFPE \\ E-mail: monicacoxbp@gmail.com
}

Artigo recebido em 28/05/2018 e aceito em 18/07/2018

\begin{abstract}
RESUMO
O presente artigo, a partir de vasta bibliografia sobre a questão dos Circuitos Alimentares e a sua utilização na criação de mercados mais justos, tem o objetivo de apresentar o percurso, as causas e as motivações que levaram ao desenvolvimento e aperfeiçoamento conceitual. A criação de conexões é o principal eixo dos Circuitos Alimentares de proximidade, indo de encontro ao distanciamento e às desconexões perpetradas pela modernidade. Desta forma, os Circuitos Alimentares de Proximidade conectam realidades antes distanciadas, como produtores e consumidores, o rural e o urbano, criando, por um lado, o acesso ao mercado justo por parte dos produtores, e por parte dos consumidores, a alimentos mais saudáveis e com maior responsabilidade social.

Palavras-chave: Desenvolvimento local sustentável, mercado global, produção agroecológica.
\end{abstract}

\section{PROXIMITY FOOD CIRCUITS: CONCEPTS, DEFINITION AND PRACTICES}

\begin{abstract}
This article, which contains a large bibliography on the issue of Food Circuits and its use in the creation of fairer markets, has the objective of presenting the course, causes and motivations that led to its development and conceptual improvement. The creation of connections is the main axis of the Food Circuits of proximity, going against the distance and disconnections perpetrated by modernity. In this way, the Proximity Food Circuits approximate previously distant realities such as producers and consumers, rural and urban, creating, on the one hand, fair market access by producers, and by consumers, to healthier foods and with greater social responsibility.
\end{abstract}

Keywords: Sustainable local development, global market, agroecological production. 


\section{INTRODUÇÃO}

A atividade comercial é inerente à vida em sociedade. É uma constante na história humana as relações de trocas de mercadorias entre os indivíduos e mesmo entre as diferentes civilizações. A produção alimentar nas sociedades agrárias, como aponta Agapio (2013), se destinava preponderantemente à auto-provisão e a comercialização dos excedentes. Assim, apesar da existência do comércio de longa distância, os sistemas alimentares dominantes tendiam a possuir uma escala regional, o que conferia aos alimentos uma identidade territorial própria.

A alimentação, muito mais que provimento de sustentação biológica, representa importante elo na relação entre homem e meio, nos dizeres de Lucci (2013) como "elemento cultural territorializado". Para serem comidos, ou comestíveis, os alimentos, ainda de acordo com Lucci (2013), precisam ser elegíveis, preferidos, selecionados e preparados ou processados pela culinária, e é aí que a alimentação ganha contornos culturais.

Nos sistemas alimentares "fechados" (ou circuitos alimentares), esses elementos culturais são mais expressivos, afinal além da questão da seleção e preparo, há o provimento de alimentos produzidos em condições regionais específicas. Tal configuração cria no "ato de comer" um ritual próprio em cada cultura, com representações simbólicas que reforçavam ainda mais esse caráter identitário entre homem e meio geográfico.

No entanto, nas sociedades modernas se verifica uma profunda metamorfose nos hábitos alimentares. A produção alimentar em escala industrial associada a um processo de comercialização extremamente polarizado nas grandes redes de supermercados e aos hábitos de alimentação urbanizados como o "fast food" e o comer fora de casa, promovem o que Cassol (2013) chama de desconexões. Vandana Shiva (2005) aprofunda esse debate trazendo o foco para a rede de agricultores e agricultoras e processos que alimentam o mundo, a tendência da localização da produção de alimentos em contraposição a agricultura industrial.

A primeira dessas desconexões é no próprio modelo de agricultura, que é industrial e intensivo e com a ampla utilização dos "pacotes tecnológicos" comerciais longos, onde a produção de determinados tipos de alimentos obedece não às relações culturais ou demandas locais, mas às demandas comerciais externas, obedecendo ao que Santos (1978) chama de longínquos centros de decisão. Outra desconexão se dá entre o rural e o urbano, causada pela distância geográfica entre locais de produção e consumo, ou

\footnotetext{
${ }^{1}$ Pacotes tecnológicos são grãos geneticamente modificados e a utilização de pesticidas e fertilizantes químicos projetados de acordo com a resistência do grão (LONDRES, 2011, P. 65).

Braz, Pereira, $2018 \quad$ ISSN 0104-5490 118
} 
entre produtores e consumidores, dada a distância social causada pela teia de intermediários entre os produtores (mesmo que estes sejam agricultores familiares) e os supermercados ou centrais de abastecimento.

E sendo esse "um fenômeno global" (MASCARENHAS, 2008, p.4), diversos autores de vários países têm se preocupado com a questão socioeconômica da alimentação, fazendo surgir uma constelação de conceitos que tratam dessa proximidade social ou geográfica da alimentação. Assim surgem autores que escrevem sobre as cadeias de alimentação territorializadas (DAROLT, 2012), cadeias curtas de comércio (SCARABELOT; SCHNEIDER 2012), ou ainda os Sistemas Alimentares Locais (CRISTÓVÃO; TIBÉRIO 2009). Ou então instituições governamentais de diversos países e regiões que institucionalizaram o conceito de Circuitos $\operatorname{Curtos}^{2}$ para a elaboração de políticas de desenvolvimento local. Esses conceitos, que apesar de diferentes possuem uma base comum, foram enfeixados neste trabalho como "Circuitos Alimentares de Proximidade", visando englobar os múltiplos conceitos que se tratam da proximidade social entre os atores desse mesmo circuito, no caso dos estudos sociológicos sobre as relações comerciais, como também os que se enfocam a questão da proximidade geográfica, como são os diversos governos que institucionalizaram o conceito para implementação de políticas de desenvolvimento regional. Os circuitos alimentares nada mais são que sistemas complexos de relações comerciais, porém de alcance delimitado e territorializado, diferenciando-se, portanto de rede, que tende a tomar proporções não delimitáveis, e diferenciando-se de "cadeias de comércio", visto que os Circuitos pressupõem uma complexidade maior nas relações comerciais, relacionando-se com os seus atores de forma não linear, como pressupõe a ideia de "Cadeia".

\section{O MERCADO MUNDIAL E A TERRITORIALIZAÇÃO DOS CIRCUITOS ALIMENTARES}

Desde a década de 1950, o geógrafo francês Pierre Monbaig (1957) alertava para a necessidade de uma geografia do capital, que investigasse o papel do capital financeiro nas atividades produtivas. As mudanças mundiais desde a década de 1990, com grande ampliação dos fluxos internacionais de capital, a potencialização de Circuitos Agroalimentares Longos, formação de sucessivas bolhas e crises financeiras trouxeram a dinâmica internacional para o

\footnotetext{
${ }^{2}$ Circuitos Curtos Agroalimentares: Sistemas alimentares localizados, que põem em contato direto consumidores produtores de gêneros alimentícios. 
centro dos debates geográficos e sobre os rumos da agricultura em particular. As mudanças espaciais ocasionadas pela dinâmica financeira na agricultura mundial são fundamentais para a análise geográfica.

O Brasil foi um dos países que ampliou mais significativamente a participação no comércio mundial de produtos agrícolas, de 2,8\% em 2000 para 5,0\% em 2010. Durante a década de 1990, esta participação havia se estabilizado em pouco mais de $2 \%$. Enquanto o total das exportações agrícolas mundiais cresceu 247,4\% no período 2000-2010, as exportações agrícolas brasileiras cresceram 443,4\%. A Rússia também apresentou expressivo crescimento das exportações de $203 \%$ de 2000 a 2007. No mesmo período, os Estados Unidos ampliaram as exportações agrícolas em 59\%, a União Européia em 112\%, a China em 137\%, a Argentina em 140\%, o Chile em 113\%, a França em 77\% e o Canadá em 40\%. Os dados demonstram que o crescimento mais intenso das exportações agrícolas ocorreu nos países periféricos. Isto se relaciona diretamente ao aumento dos investimentos financeiros nos produtos agropecuários após as inúmeras crises financeiras da década de 1990.

Os países da Ásia, além do crescimento das exportações, ampliaram significativamente as importações. O crescimento econômico da região possibilitou melhoria das condições de alimentação de milhões de pessoas, levando ao aumento das importações. É importante ressaltar que não se trata apenas de aumento no consumo de alimentos, mas de uma mudança qualitativa. A China, por exemplo, vem passando por mudança nos hábitos da população, semelhante ao que ocorreu no Japão nas décadas de 1960/70, com aumento do consumo de proteínas animais e de óleos vegetais e estabilização do consumo de produtos tradicionais como o arroz. Esta mudança é semelhante a que ocorreu no início do século XX nos países da Europa ocidental, como discutiu Guglielmo (1975) e em período mais recente no Brasil, como discutido em estudos de geógrafos como Carvalho (2001) e Medeiros (2009; 2010).

A década de 1990 no Brasil foi marcada por profundas crises sociais e financeiras, o que trouxe uma política de cortes de recursos para a agricultura, o que levou a inúmeras situações, como escassez de recursos para financiamento agropecuário e aumento das taxas de juros; agravamento das crises dos produtores com dívidas mais antigas, levando a sucessivas renegociações; crise generalizada da agricultura, especialmente dos pequenos e médios produtores, com poucas alternativas de financiamento; busca de novas fontes de financiamento, especialmente pelos grandes produtores ligados ao setor agroindustrial ou aos mercados externos. 
Junto à ampliação do comércio de mercadorias, tem-se o aumento dos fluxos internacionais de capital e dos investimentos em mercados futuros de commodities. $\mathrm{O}$ grande aumento do consumo de alimentos, em especial nos países asiáticos, coberto via importações, estimulou os movimentos especulativos em torno das commodities agrícolas. Assim, as expectativas em torno do aumento do consumo de produtos agrícolas, num momento de ciclo ascendente de preços, aceleraram ainda mais a elevação dos preços no mercado mundial.

Este panorama, que Banks (2003) denomina “comoditização" dos mercados de alimentos, traz significativas mudanças para a dinâmica agroalimentar, onde os alimentos passam a ser tratados como "mercadorias", perdendo todo e qualquer valor de identidade social, quebrando, desta maneira, o vínculo com a figura do agricultor, e também a perda da identidade regional dos alimentos, visto que eles, além de cruzar enormes distâncias geográficas, passam por intrincadas teias de relações comerciais até surgirem como produto final nas prateleiras.

Ploeg (2006) destaca que o processo de modernização agrícola, também conhecida "revolução verde", possibilitou profundas modificações na base produtiva da agricultura, com a introdução, de acordo com Pereira (2012), de novas sementes e seu respectivo "pacote tecnológico" de fertilizantes, herbicidas, pesticidas, crédito, obras de infraestrutura, serviços de extensão e treinamento. Pereira (2012) ressalta que o pacote tecnológico da revolução verde foi concebido como um pacote industrial conjugado ao difusionismo tecnológico e a base ideológica de valorização do progresso.

O mercado de futuros, onde a produção é comercializada já antes do plantio, é um exemplo claro do uso de pacotes tecnológicos como "garantias contra imprevistos". De acordo com Londres (2011), os agricultores de pequeno e médio poder aquisitivo só tem acesso ao crédito depois de adquiridos os pacotes tecnológicos: grãos especializados, herbicidas, fertilizantes químicos e etc.

No que se refere à América Latina, novamente Ploeg (2006) destaca que o programa de reforma agrária massiva no Peru (no período 1969-1975) promoveu tipicamente a modernização; no México, tentou-se primeiramente implementar uma revolução verde do tipo asiático e, posteriormente, o meio rural passou a ser literalmente modificado por um forte processo de "pecuarização" (PLOEG, 2006), assim como ocorrera em vários outros países da América Central e do Sul. No Brasil, foi especialmente a substituição dos cultivos de café pelos de soja que representou uma primeira expressão, ampla e massiva, da modernização. 
Assim, podemos observar que independente de sua forma específica, ou das especificidades dos vários contextos, a modernização implicou em aumentos significativos da produtividade e um "abrupto e multifacetado processo de mercantilização" (PLOEG, 2006, p 17), vinculando a produção massiva diretamente aos mercados globais. A estas teias de relações de grande escala e que envolvem múltiplos atores, se dão o nome, para Mundler (2013) de "sistemas alimentares globais".

Esse modelo passou a ser alvo de intensas críticas, desde o campo socioeconômico até o ambiental, o público para Guivant (2003) tem se preocupado cada vez mais com questões ecológicas e com a qualidade daquilo que consomem, fazendo com que se generalizasse a desconfiança sobre esses produtos. Com a dissociação da produção e do processamento dos alimentos, os órgãos de fiscalização passaram a desenvolver um papel importante frente aos mercados, mas a opinião pública frente agropecuária passou a ser dominada por um contínuo fluxo de escândalos.

Mas desde meados da década de 1990, diante à essa massificação e ampla polarização comercial, surgem cada vez mais iniciativas que de Circuitos produtivos que se situam fora do modelo agropecuário convencional. De acordo com Becker e Cabedo (2012), diferentes atores sociais têm vindo a manifestar-se contra a crescente padronização das escolhas alimentares. Tais reações acontecem "em consequência da crise do modelo quantitativo (consumo de massas) na qual a qualidade, tanto dos produtos quanto dos processos, passa a ser o objetivo central" (CABEDO, 2010).

Observando mais de perto esses fenômenos, é possível afirmar, como Banks (2003), que essas "novas modalidades" nada mais são do que a adaptação (ou mesmo uma ação de resgate, em alguns lugares) de seculares tradições camponesas de produção para o consumo próprio e venda dos excedentes. Em determinados contextos, segundo Goodman (2004) esses novos circuitos alimentares são uma inovadora estratégia de mercado, que tem em vista a diminuição de custos através da venda direta, em outros, no entanto, são formas de resistências de um modo de vida tradicional frente às imposições da modernização agrícola, em outros ainda, a fuga para um modelo de produção-comércio alternativo.

As primeiras iniciativas em circuitos alimentares localizados, de acordo com Banks (2003), aconteceram nos Estados Unidos com os "Farmers Market" (figura 1). O país que se destaca pelo modelo industrial de produção agrícola, e pela existência das maiores redes de "fast food" do mundo. Esses movimentos são, para Cristóvão e Tibério (2009), muito fragmentados, desiguais de espaço para espaço que tendem a valorizar o estilo de vida de 
dada população, de distintos grupos étnicos e sociais, que buscam subsistência e valorização identitária, como é o caso dos "Farmers markets" (figura 1).

Figura 1- Farmers Markets nos Estado Unidos

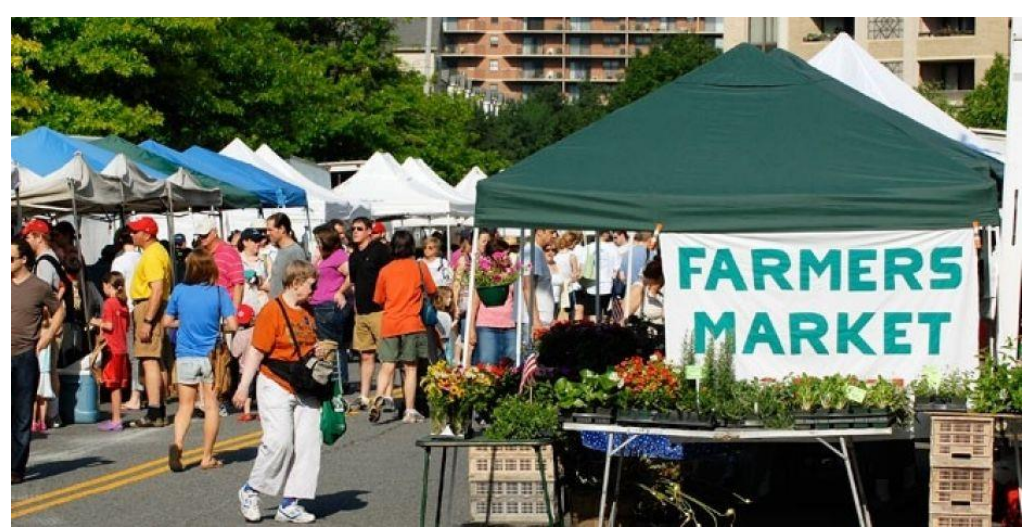

Fonte: FOXBUSINESS (2017).

Para além de "local food" também se aspira a produzir "sustainable food", a partir do modo de produção sem agrotóxicos e de outras formas naturais que excluam o uso de insumos químicos. A questão da distância geográfica, ainda segundo Cristóvão e Tibério (2009) está também no centro do debate, pois se deseja reduzir o número de quilômetros percorridos pelos alimentos.

Os objetivos centrais desta territorialização da cadeia alimentar são, de acordo com Cristóvão e Tibério (2009, p. 9):

1) a dinamização do consumo de alimentos regionais, ou seja, produzido localmente; 2) o estabelecimento de ligações entre produtores e consumidores; 3 ) a revitalização de estruturas tradicionais de produção, transformação e distribuição; 4) a construção de redes de relações entre produtores e governos locais, empresários, restaurantes ou lojas especializadas; e 5) a promoção da economia local e do desenvolvimento rural.

Este tipo de movimentos, que visam reconstruir Circuitos Alimentares de Proximidade, ligando produtores e consumidores e têm se expandido por várias zonas do globo, em particular na Europa, com especial relevo para França, Itália, Bélgica, Espanha e Portugal e América Latina, sobretudo no Brasil e na Argentina. E em consonância com essas novas práticas, surge um vasto número de autores que se preocupam com essa questão da

\footnotetext{
${ }^{3}$ Um dos slogans mais representativos dos Farmers Markets é "Buy Fresh, Buy Local" 
proximidade entre consumidores e produtores e com os circuitos alimentares, o que culmina numa multiplicidade de conceitos muito próximos em si. Dessa forma, é possível encontrar na literatura termos como "foodshed" aludindo para a unidade entre o local, as pessoas, a natureza e a sociedade e a "Civic Agriculture" (Lyson, 2004) entendida como o sistema de produção agrícola e alimentar enraizada num local, baseada em recursos locais, servindo mercados e consumidores locais e empenhada na justiça social, sustentabilidade ecológica e relações sociais de benefício mútuo (CRISTÓVÃO; TIBÉRIO, 2009).

Por sua vez, Murdoch (2000) fala em "cadeias alimentares alternativas (alternative supply chains) e Muchnik (2002) desenvolveu o conceito de sistemas agroalimentares localizados - SIAL (localized agri-food system). Importante observar que Murdoch se refere a essas práticas de mercado como "alternativas" deixando claro que essas formas de comercialização não estão vinculadas com o mercado "convencional”. Ao passo que Muchnik utiliza o termo "sistema" e não "cadeia" alimentar, para ele as relações de comercialização local envolvem uma teia de atores, um sistema, que não obedece a um padrão linear.

Muito semelhante é o termo cunhado por Feenstra (2006), denominado de "Sistema Alimentar Local", que de acordo com Cristóvão e Tibério (2009), representa um esforço colaborativo para construir economias alimentares autossustentadas e baseadas no local, em que a produção, transformação e distribuição e consumo são integrados de forma a melhorar a economia, o ambiente e a saúde social de um lugar específico.

Para Darolt (2012), que estuda a ocorrência desse conjunto de relações comerciais na França e no Brasil, denomina esse fenômeno como "redes alimentares alternativas", para ele, existe um vínculo estreito entre essa proximidade entre produtores e consumidores e a produção de produtos orgânicos e agroecológicos. Concomitantemente, Marechal (2008) que usa o termo "Circuitos locais" (Circuits Locaux) ou "Circuitos Curtos" (Circuits Courts), mostra que na maioria dos casos, os Circuitos Curtos se associam à produção orgânica (bio) e com a agricultura familiar. Ao estudar a região francesa da Bretanha, observando o elevado número de produtores que comercializam em venda direta, Marechal (2008, p.59) afirma que:

Les organisations de développement agricole qui se sont intéressées à cette question travaillent en même temps à la promotion de pratiques de production écologiquement saines (agriculture durable et biologique) et à celle des circuits courts de comercialisation. 
Uma noção abrangente que enquadra este tipo de relação de proximidade social é o já mencionado conceito de Circuitos Curtos. O economista francês Louis Malassis, ainda nos anos de 1970, na sua principal obra: "Economie Agroalimentaire" (1973), utilizou o conceito de circuitos para tratar os graus progressivos de complexidade na estruturação do abastecimento alimentar com o número de agentes e a distância a ser percorrida entre o local de produção e consumo.

Para este autor, os circuitos alimentares são dotados de extensões muito variadas porque a possibilidade de que apareçam a escalas cada vez maiores não é um fato absoluto, e vai depender das condições encontradas pelo sistema alimentar, em seu processo evolutivo para estabelecer conexões entre pontos distantes no espaço, como efeito da modernização dos meios de transporte e do incremento de tecnologia ao longo das cadeias produtivas. Malassis (1973) ainda acrescenta que o sistema alimentar se estrutura de acordo com cada formação social e econômica, o que concorre para a hipótese de que o sistema agroalimentar evoluiria de forma heterogênea (entre cadeias produtivas) e desigual (entre territórios).

Mas este conceito, fundamentado na realidade francesa, e desenvolvido por um conjunto de autores, dentre eles Marechal (2008) Chaffotte e Chiffoleau (2007) ganha corpo somente no início dos anos 2000. Os Circuitos Curtos se caracterizam, de acordo com Chaffott e Chiffoleau (2013, p. 4):

Pela relação direta entre produtor e consumidor, ou por no máximo um intermediário entre os dois, sendo a curta distância social entre os agentes envolvidos que seria a característica principal desse Circuito comercial, o desenvolvimento local, a transparência comercial e a valorização cultural, permitindo que o agricultor utilize suas próprias relações culturais e sociais no processo de produção e venda.

Os "Circuitos Curtos" (Circuits Courts), que é o conceito mais popularizado na França (FRANCE, 2016, p.1), ganha uma definição institucional do ministério da Agricultura francês:

Um Circuito Curto é um modo de produção agrícola exercido através da venda direta do produtor ao consumidor, e através da venda indireta, com a condição de que haja no máximo um intermediário entre o produtor e o consumidor.

Paralela a esta concepção, Chiffoleau (2007) também caracteriza os chamados Circuitos alimentares longos, que possuem (1) escalas maiores de venda, revenda e distribuição, que denotam um distanciamento Geográfico entre os agentes envolvidos, 2) mas 
mesmo assim, há a preservação da identidade alimentar, sendo possível ao consumidor identificar o respectivo produtor e a forma que ele foi produzido, mas sem que tenha um contato direto e uma relação pessoal com o produtor (os circuitos curtos e longos são ilustrados na figura 1). Segundo Mundler (2013), os circuitos alimentares curtos não são impermeáveis, podendo então um mesmo agricultor fazer parte de diversos circuitos distintos, aumentando ainda mais a complexidade do estudo desses fenômenos.

A figura 2 apresenta o esquema de circuitos curtos, em relação ao mercado convencional, de acordo com a concepção do ministério de Agricultura da França (2014).

Figura 2 - Esquema de Venda Direta, caracterizando Circuito Alimentar Curto.

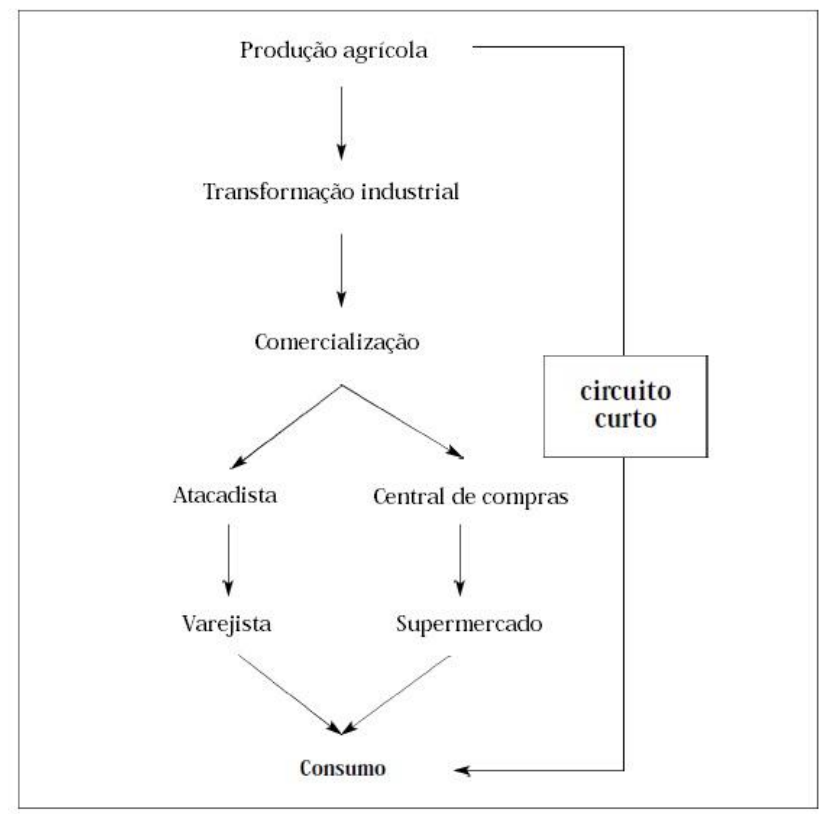

Fonte: (Darolt, 2013).

Em 2012, o Conselho governamental da região administrativa de Pays de la Loire, na França, formalizou o conceito de Circuitos Alimentares de Proximidade, de acordo com Jacques Auxiette, presidente do conselho regional de Pays de la Loire (2012, p.109):

A região de Pays de la Loire deseja desenvolver uma agricultura durável, plural, ancorada no território e que atenda às inspirações cidadãs. Para concretizar essa ambição, se faz necessário formalizar a noção de Circuitos Curtos Alimentares, através desta carta regional.

Nesta carta, diferentemente das concepções anteriores, confere aos Circuitos Curtos, ou Circuitos alimentares de proximidade. 
A noção de extensão, pois ela delimita uma distância máxima de $80 \mathrm{~km}$ entre local de produção e consumo: “[...] a prioridade será dada aos projetos que garantam uma alimentação de origem regional ou em departamentos limítrofes, dentro de um limite de $80 \mathrm{~km}$ entre o lugar de produção e de comercialização".

Nos estudos preliminares para a implantação de políticas governamentais que envolvem Circuitos Curtos na região administrativa de Pays d'Ancenis (2015, p.109), também na França, essa delimitação se estende a 150 km:

Nous avons retenu pour cette étude le vocable utilisé par l'ADEME (Agence de l'Environnement et de la Maîtrise de l'Énergie) de « circuit alimentaire de proximité», circuit qui répond principalement à deux critères: circuit de vente directe ou avec un (voire deux) intermédiaires (= circuit court); e distance limitée (généralement inférieure à $150 \mathrm{~km}$ ) entre le lieu de production et le lieu de consommation ${ }^{4}$.

Segundo Chaffotte e Chiffoleau (2007), o apoio governamental aos circuitos curtos na França permitiu uma aproximação entre consumidores e produtores, uma melhor remuneração do produtor, preços justos ao consumidor, incentivo à produção local, gerando empregos e dinamizando a economia local.

Essa institucionalização do conceito de Circuitos Curtos permitiu o fomento de iniciativas por parte da própria união Europeia (FRANCE, 2016, p.4):

La politique agricole commune et la politique européenne de développement rural soutiennent directement et explicitement les circuits courts; près de 800 millions $€$ ont été affectés dans la programmation 2014 - 2020 pour le soutien d'action de coopération et de promotion dans ce domaine.

Também em Portugal sugiram definições governamentais que tratam dessa aproximação produtor-consumidor e valorização dos produtos regionais. Assim, na tentativa de sistematizar algumas destas ideias e estabelecer algum consenso em torno de uma linguagem comum, fora criado o Grupo de Estratégia para a Valorização da Produção

\footnotetext{
${ }^{4}$ Para este estudo, utilizamos o termo usado pela ADEME (Agência Francesa de Meio Ambiente e Energia) como um "circuito alimentar de proximidade", um circuito que atende principalmente a dois critérios: um canal de vendas diretas ou com um (ou dois) intermediários (= curto-circuito); A distância limitada (geralmente menor que $150 \mathrm{~km}$ ) entre o local de produção e o local de consumo. (tradução própria)
} 
Agrícola Local (GEVPAL) no âmbito do Ministério da Agricultura, Mar, Ambiente e Ordenamento de Território (MAMAOT), com o objetivo de elaborar a "Estratégia para a valorização da produção agrícola local”. Assim, foram estabelecidos os seguintes conceitos (MAMAOT, 2013):

a) Sistema Alimentar Local (SAL): Um conjunto de atividades interligadas, em que a produção, a transformação, a distribuição e o consumo de produtos alimentares visam promover a utilização sustentável dos recursos ambientais, econômicos, sociais e nutricionais de um território. Este é definido como uma comunidade de interesses localizados, reforçando as relações entre os respetivos agentes intervenientes;

b) Circuito Curto Agroalimentar (CCA): Um modo de comercialização que se efetua ou por venda direta do produtor para o consumidor ou por venda indireta, com a condição de não haver mais de um intermediário. A ele se associa uma proximidade geográfica (conselho e conselhos limítrofes) e relacional entre produtores e consumidores.

As iniciativas em Circuitos Curtos na província canadense de Québec impulsionaram o ministério de Agricultura, Pesca e Alimentação (MAPAQ) a implementar programas de fomento aos Circuitos Curtos. Para isso, também houve uma formalização governamental do conceito para o "programme proximité”. Assim, conforme transformação Mundler ( 2015, p. 64) eram admitidos Circuitos Curtos como:

Formas de mercado que compreendem os sistemas de comercialização que favorizam uma maior proximidade relacional e geográfica entre os agentes do setor bioalimentar e os consumidores. A proximidade relacional faz referência aos circuitos curtos de comercialização, que admitem no máximo um intermediário na distribuição entre a produção agrícola ou de transformação alimentar artesanal e o consumidor. A proximidade geográfica corresponde a comercialização no seio da própria região ou a menos de $150 \mathrm{~km}$ de distância entre do lugar de produção ou transformação.

Segundo Mundler (2013), que faz detalhado estudo de caso em três regiões da província canadense de Québec (Lac-St-Jean-Est), Lotbinière e Brome-Missisquoi, os circuitos alimentares de proximidade trazem importantes contribuições ambientais, sociais e econômicas, influenciando no bem-estar dos agricultores e da comunidade em geral. No Brasil, apesar de não existir uma definição muito clara do seriam esses Circuitos Alimentares, há uma forte tradição de existência dos mesmos, de acordo com Cassol (2013), sobretudo, em regiões de maior tradição camponesa, como o Nordeste e o Sul. 


\section{CONSIDERAÇÕES FINAIS}

Observando o paulatino desenvolvimento de uma constelação de conceitos muito semelhantes, que tratam da aproximação social entre produtores e consumidores do setor alimentar, se soma à questão territorial da produção de alimentos. A definição de Circuitos Alimentares de Proximidade não se refere apenas à proximidade entre os sujeitos, mas também à proximidade geográfica, dando um caráter identitário aos alimentos e possibilitando uma maior transparência nas relações de comercialização e no papel dos agricultores que produzem a base da alimentação da humanidade. Desta forma, é possível pontuar que os Circuitos alimentares de proximidade são relações comerciais localizadas, em uma dada porção específica do espaço, que não apenas trazem a questão da proximidade geográfica, como também possibilita a proximidade social, pondo em contato os sujeitos dos Circuitos: agricultores e consumidores.

\section{REFERÊNCIAS}

AGAPIO, Roberto. Feira livre. Disponível em: http://www.robertoagapio.fot.br/texto01.htm. Acesso em: 13 de outubro de 2013.

BANKS, J. Understanding alternative food networks: exploring the role of short food supply chains in rural development. An environment and planning, London, v. 35, p. 393-411, 2003.

BECKER, Cláudio e CARMEN Lozano Cabedo. Como construir a Qualidade Agroalimentar: Análise de experiências brasileiras e espanholas. Rev. De Economia Agrícola, 59 (2), pp.115-129.

CARVALHO, M. S. Lugares e Paladares: Uma contribuição geográfica à diversidade do consumo alimentar no brasil. RA`E GA- O Espaço Geográfico em Análise, Curitiba, n. 15, p. 95-111, Editora UFPR. 2008. 
CASSOL, A. P. Redes Agroalimentares alternativas: Mercados, interação social, e a construção social da confiança. 2013. 186p. Dissertação (mestrado) da Sociologia Universidade Federal do Rio Grande do Sul. Porto Alegre, 2013.

CHAFFOTTE, L., CHIFFOLEAU, Y. Vente directe et circuits courts: évaluations, définitions, typologie, Les cahiers de l'observatoire C.R.O.C, n¹, 8 p. 2007.

CHIFFOLEAU, Y., GAUCHE, A. Diversité des stratégies et des performances dans les circuits courts alimentaires: une analyse croisée, Vème Congrès de l'AFS, 18 p. 2013.

CRISTÓVÃO, Artur; TIBÉRIO, Luis. Comprar Fresco, Comprar Local: Será que temos algo a aprender com a experiência americana? Cultura, Inovação e Território, o Agroalimentar e o Rural, p. 27-34. Lisboa: SPER. 2009.

DAROLT, M. R. Conexão Ecológica: novas relações entre agricultores e consumidores. Londrina: IAPAR, 2012. 162 p.

FEENSTRA, R. New evidence on the gains from trade. Review of World Economics, 142p. London. 2006.

FRANCE. Consommation: manger local partout en France. Disponível em: http://agriculture.gouv.fr/consommation-manger-local-partout-en-france. Acesso em 23 de Junho de 2016.

GOODMAN, D. Rural Europe redux: reflections on alternative agro-food networks and paradigm change. Sociologia Ruralis, Wageningen, v. 44, n. 1, p. 3-16, 2004.

GUGlelmo, R. Um Novo Capítulo da Geografia: a Geografia do Consumo e da Distribuição. In: GEORGE, Pierre et al. A Geografia Ativa. 4ª ed. São Paulo: Difel, 1975.

GUIVANT, J. S. Os supermercados na oferta de alimentos orgânicos: apelando ao estilo de vida egotrip. In: Ambiente \& sociedade, Campinas, Unicamp, v. VI, n. 2, p. 63-82, 2003. 
LUCCI, Pedro Henrique Gomide. Geografia dos Alimentos no Espírito Santo. Dissertação - UFES. Vitória. P.327. 2013.

LYSON, T. (2004). Civic Agriculture: Reconnecting Farm, Food, and Community. Medford, MA: Tufts University Press.

MALASSIS, L. Agriculture et processus de developpement. Essai d'orientation pedagogique. Paris, Unesco, 1973. 308 p.

MARECHAL,G. Les circuits courts alimentaires: bien manger dans les territoires. Paris: Ed. Educagri, 2008. 216 p.

MASCARENHAS, G; DOLZANI, M.C.S. Feira livre: territorialidade popular e cultura na metrópole contemporânea. Revista Eletrônica Ateliê Geográfico, UFG/IESA v. 2, n. 4, agosto/2008.

MEDEIROS, M.C. A geografia do consumo de alimentos e a dinâmica do setor agroalimentar brasileiro. Cadernos Geográficos (UFSC), v. 23, p. 07-89, 2010.

MEDEIROS, M.C. A Geografia Econômica do Setor Agroalimentar Brasileiro: Investimentos, Recursos Ociosos e Dinâmica Cíclica (1990-2007). FFLCH//USP (Tese de Doutorado em Geografia Humana). 2009.

MONBEIG, Pierre. Novos estudos de geografia humana brasileira. São Paulo: Difusão Européia do Livro, 1957.

MUCHNIK, J., REQUIER-DESJARDINS, D., SAUTIER, D., \& TOUZARD, J. M. Systemes agroalimentaires localisees. Economies et Sociétés AG, 29, 1465-1484. 2007.

MUCHNIK, José. Les Systèmes Agroalimentaires Localisés: intérêt, approche, interrogatios. Exposé Introductif - Colloque SYAL. GIS SYAL: Montpellier, outubro de 2002. 
MUNDLER, P. Le prix des paniers est-il un frein a l'ouverture sociale des AMAP? Une analyse des prix dans sept AMAP de la Region Rhone-Alpes. Économie rurale. Agricultures, alimentations, territoires(336), 3-19. Québec. 2013.

MUNDLER, P. Le prix des paniers est-il un frein a l'ouverture sociale des AMAP? Une analyse des prix dans sept AMAP de la Region Rhone-Alpes. Économie rurale. Agricultures, alimentations, territoires(336), 3-19. Québec. 2013.

MUNDLER, P. Viabilite et perennite des "petites fermes". Enseignements tires de deux projets de recherche. Courrier de l'environnement de l'INRA, 61, 57-68. 2011.

PAYS D'ANCENIS. Les circuits courts alimentaires de proximité en pays d'ancenis. Ancenis. Jan. 2015. 109 p.

PAYS DE LA LOIRE. Charte: Circuits Alimentaires de proximité et de qualité. Nantes. 2012. 16 p.

PEREIRA. Mônica Cox de Britto. Revolução Verde. In: CALDART, Roseli Salete;

PEREIRA, Isabel Brasil; ALENTEJANO, Paulo; FRIGOTTO, Gaudêncio. Dicionário da Educação do Campo. Rio de Janeiro, São Paulo: Escola Politécnica de Saúde Joaquim Venâncio, Expressão Popular, 685-691, 2012.

PLOEG, Jan Douwe van der. O modo de produção camponês revisitado. In: SCHNEIDER, Sérgio (Org.). A diversidade da agricultura familiar. Porto Alegre: UFRGS, 2006. p. 13-54.

SANTOS, Milton. Por uma Geografia Nova. São Paulo: Hucitec, 1978.

SCARABELOT, M. \& SCHNEIDER, S. As cadeias agroalimentares curtas e desenvolvimento local: Um estudo de caso do município de Nova Veneza, SC. Revista Faz Ciência V.15 (20). 101-130. 2. Florianópolis. 2012. 
SHIVA, Vandana. "Biodiversidade, Direitos de Propriedade Intelectual e Globalização" In: SANTOS, Boaventura de S. (org.) Semear Outras Soluções: os caminhos da biodiversidade e dos conhecimentos rivais. Rio de Janeiro: Civilização Brasileira, 2005. 